\title{
Convergence of Health Expenditure in OECD Countries: Evidence from a Nonlinear Asymmetric Heterogeneous Panel Unit Root Test
}

\author{
Didem Pekkurnaz
}

\author{
University of North Carolina at Chapel Hill (UNC-CH), Department of Economics, 107 Gardner Hall, NC \\ 27599, USA
}

\begin{abstract}
This paper examines the convergence in health expenditure across 22 OECD countries between 1980 and 2012 by implementing panel unit root tests. Contribution of application of the nonlinear asymmetric heterogeneous panel unit root test is twofold. Firstly, it relaxes the assumption of cross-sectional dependency in panel data. Secondly, it incorporates the asymmetric nonlinear mean reversion in a panel setting. Results show that while the conventional panel unit root test cannot reject the null hypothesis of a unit root in relative per capita health expenditures for the whole set of countries, both the symmetric and the asymmetric nonlinear panel unit root tests indicate the stationarity of the panel. Specifically, almost 23 percent of the countries are found to be converging by employing the nonlinear asymmetric panel unit root test. In addition, introducing asymmetric structure helps to uncover additional converging countries which cannot be detected using linear and nonlinear symmetric panel unit root tests.
\end{abstract}

Keywords: Health care expenditures, Convergence, Nonlinear asymmetric panel unit root tests, OECD Countries.

\section{INTRODUCTION}

According to the Organization for Economic Cooperation and Development (OECD) Health Statistics 2014, OECD average per capita health care expenditure (US\$ PPP) and health expenditure as share of GDP have been rising over the period 20002012 although there has been a decline between 2009 and 2011 due to global financial crisis. The United States (US) has always been the country with the highest spending on health over the period 2000-2012. Health spending accounts for $16.9 \%$ of GDP in US in 2012, which is higher than OECD average $9.3 \%$. Turkey and Mexico, on the other hand, have the lowest per capita health expenditures in 2012 (less than a third of the OECD average). The estimated average growth rate of per capita health expenditure across OECD countries is $4.1 \%$ between 2000 and 2009 while between 2009 and 2011 the growth rate is only $0.2 \%{ }^{1}$ Although US has the highest per capita health expenditure among OECD countries, its growth rate on per capita health spending, in real terms, over the period $2000-2009$ is $3.4 \%$ which is less than the growth rates of countries such as Korea and New Zealand (9.3\% and $4.5 \%$ respectively) with per capita health expenditures lower than OECD average for the period 2000-2009.

*Address correspondence to this author at the University of North Carolina at Chapel Hill (UNC-CH), Department of Economics, 107 Gardner Hall, NC 27599, USA; E-mail: didempnz@gmail.com

${ }^{1}$ See OECD (2013) for details
Countries' spending on health care and the rate at which it grows depend on different market and social factors, differences in organization and financing of health care systems, and the level of technology of countries. Improvements in medical technologies, population aging and rising consumer expectations lead to increase in health expenditure growth (Huber and Orosz 2003). Newhouse (1992) conjectures that technological advancement is a major contributor to health care expenditure accounting for almost $75 \%$ of increase in health expenditures. Okunade and Murthy (2002) econometrically test this hypothesis for US and confirm that changes in R\&D spending (proxy for the technology) is a long run factor of rising health care expenditure. Another factor affecting health expenditure is population aging. Since health expenditure per person for older people is greater than health expenditure per person for younger people, countries with rising older population might experience rising health expenditure. In addition to these, different environmental conditions and lifestyles might also generate differences in types of diseases experienced across countries which may lead to varying levels of health expenditures.

Considering the differences in health expenditures across countries, concept of convergence in health expenditures has been investigated by many researchers. Economic convergence is based on neoclassical growth theory. The theory states that in the long run countries with similar preferences and technology will reach to a common steady state level of income per capita. Poor countries tend to grow faster than rich ones and eventually they will catch-up. Since health expenditure rises when income expands, health 
expenditure may also convergence as income converge between countries. This has been the motivation for the literature on convergence in health expenditures between countries. As countries develop and grow over time, consumers may demand for new medical services and procedures due to the availability of knowledge about health capabilities around the world. Thus, increasing expectations from consumers may lead to utilization of new procedures in countries and contribute to the convergence in health expenditures. Moreover, integration of health systems and introduction of common policies regarding health care markets may also lead to convergence in health expenditures.

Except for the work by Lau, Fung and Pugalis (2014), analysis of health care expenditure convergence has been generally implemented by linear unit root tests such as panel unit root test developed by Im, Pesaran and Shin (2003) and LM panel unit root test. However, as pointed out by Lau et al. (2014), health care expenditure may follow a nonlinear path. Thus, to account for nonlinearity, the panel unit root test developed by Ucar and Omay (2009) is employed in this paper in addition to the conventional linear panel unit root test. The nonlinear symmetric unit root test proposed by Ucar and Omay (2009) is an extension of the time series unit root test developed by Kapetanios, Shin and Snell (2003) (henceforth, KSS) into a panel setting. Although, Ucar and Omay (2009) deal with nonlinearity, they ignore the possibility of asymmetric behavior. However, per capita health expenditures of OECD countries show asymmetric behavior (Narayan 2009). Thus, to take asymmetry into account, a nonlinear asymmetric panel unit root test proposed by Emirmahmutoglu and Omay (2014) is also implemented in this paper. This test is an extension of asymmetric time series unit root test introduced by Sollis (2009) into a panel context. To deal with the problems that stem from cross-sectional dependence, both Ucar and Omay (2009) and Emirmahmutoglu and Omay (2014) employ the Sieve bootstrap methodology by Chang (2004), which is also used in this research. Furthermore, as emphasized by Taylor and Sarno (1998), panel unit root tests may reject joint nonstationarity even if only one of the series in the panel is stationary. Therefore, it is very essential to separate the panel into stationary and non-stationary series if the null hypothesis of a unit root is rejected. A sequential panel selection method (SPSM) developed by Chortareas and Kapetanios (2009) is implemented in this research to identify stationary series in the panel.
In summary, this paper examines the convergence in per capita health expenditures for 22 OECD countries between 1980 and 2012 by comparing the results from aforementioned three panel unit root tests developed by Im, Pesaran and Shin (2003) (henceforth, IPS), Ucar and Omay (2009) and Emirmahmutoglu and Omay (2014). Contribution of this paper are twofold. Firstly, the asymmetric nonlinear panel unit root test applied in this research relaxes the assumption of cross-sectional dependence by implementing the Sieve bootstrap methodology proposed by Chang (2004) and secondly, it also allows for the asymmetric nonlinearity. To the author's knowledge, this is the first application of a nonlinear asymmetric heterogenous panel unit root test for the concept of convergence in health care expenditures across countries. According to the IPS test, per capita health expenditures for countries as a panel do not converge to OECD mean while the symmetric panel unit root test results indicate that only one per capita health expenditure series converges to OECD mean. Finally, the null hypothesis of a unit root for 5 out of 22 OECD countries are rejected by the asymmetric panel unit root test. Thus, it can be argued that incorporating asymmetric behavior when analyzing the convergence in per capita health expenditure across countries helps to uncover additional countries with per capita health expenditures converging towards OECD mean.

Organization of this paper is as follows. Section 2 discusses the literature on convergence in health expenditure. Data and methodology are described in Section 3. Section 4 presents the results and Section 5 concludes.

\section{LITERATURE REVIEW}

Convergence in health expenditure across countries has been investigated by many researchers. However, the findings of those studies are mixed. Some prior studies using data for (European Union) EU countries have found evidence of convergence in health expenditures towards EU mean. For instance, Nixon (2000) examined $\sigma$-convergence in health care expenditures of $15 \mathrm{EU}$ countries between 1960 and 1995 and $\beta$-convergence in health care expenditures of the same countries between 1980 and 1995. $\sigma$ convergence is obtained by examining the change in the standard deviation or coefficient of variation of indicators e.g. health expenditures across countries. This method examines how dispersion between indicators across countries has changed. For instance, if the value of standard deviation of health expenditures 
across countries diminishes we say that $\sigma$-convergence exists. $\beta$-convergence exists if a poor economy catches up with the rich one in terms of the indicator e.g. health care expenditure by growing faster than the rich country. Results showed upward convergence in health care spending of Southern Mediterranean countries' towards EU mean while downward convergence in health care expenditures of EU countries of the North. Hitiris and Nixon (2001) studied the $\beta$-convergence in health care expenditure per capita and health care expenditure as a share of GDP for a panel of $15 \mathrm{EU}$ countries between 1980 and 1995. Findings showed the existence of convergence towards EU mean in both health expenditure measures. Specifically, both absolute and conditional convergence were evident in per capita health care expenditures whereas only absolute convergence was supported for the health care expenditure as a share of GDP variable. Absolute convergence relies on the assumption that countries converge to a common steady state while conditional convergence implies that countries converge their own state states which may be different than each other. In addition to these, they also investigated the health care expenditure convergence towards EU mean for three country groups constructed based on the health care system of countries. Results indicated the absolute convergence in both health care expenditure measures and confirmed the general expectation of higher health care expenditures of countries adopted Social Insurance $(\mathrm{SI})$ than that of countries with National Health Service (NHS).

Kerem, Püss, Viies and Maldre (2008) analyzed the $\sigma-, \beta$ - and $\gamma$-convergence in health care expenditures of EU countries using cross-sectional data for the period 1992-2004. $\gamma$-convergence is measured by the Kendall's rank concordance index which helps to estimate the changes in a country's ranking. The closer the index is to zero the greater the extent of mobility within the distribution (Boyle and McCarthy 1999) and $\gamma$-convergence occurs. Results also confirmed $\sigma$ convergence for health expenditures of EU-23 countries. On the other hand, non-convergence of health expenditures or only a weak evidence of convergence for EU countries have also been shown. For example, Montarani and Nelson (2013) analyzed the development in three healthcare dimensions (coverage, financing which includes health care expenditures and provision) of 19 EU countries over the period 1980-2006. Convergence was observed only in private healthcare financing i.e. countries became similar in increased private healthcare financing while other dimensions such as health employment and healthcare provision were shown to be diverging.

Convergence of health expenditures in OECD countries has also been examined but studies have produced contradicting results. Alcalde-Unzu, Ezcurra and Pascual (2009) decomposed the disparities in per capita health expenditures of 21 OECD countries over the period of 1975-2003 using Theil's second measure of inequality. Results indicated that decreases in the level of per capita health expenditure inequality among countries was due to the convergence of factors: health care expenditure as a share of GDP, labour productivity, employment rate and the ratio of workingage population to total population. Fallahi (2011) studied the stochastic and $\beta$-convergence of health expenditures as a share of GDP for 11 OECD countries over the period 1960-2006. Stochastic convergence was tested with and without a structural break using stationarity test of Kwiatkowski-Phillips-Schmidt-Shin (1992) (henceforth, KPSS) and the minimum LM type statistic developed by Lee and Strazicich (2003). Similarly, $\beta$-convergence was also tested with a structural break using an econometric method by Vogelsang (1998). Results showed that stochastic convergence existed for all OECD countries while $\beta$ convergence towards health expenditure as a share of GDP for US was evident only for 4 countries before the structural break points. Schmitt and Starke (2011) found the conditional convergence as well as absolute $\beta$-convergence for various social expenditures including health for 21 OECD countries between 1980 and 2005 employing error correction models. Panopoulou and Pantelidis (2012) analyzed the convergence in per capita health expenditures of 19 OECD countries over the period of 1972-2006 using the method introduced by Phillips and Sul (2007). Findings indicated that 17 out of 19 countries converged in per capita health expenditures whereas US and Norway followed a different path.

Although aforementioned studies on OECD countries have suggested convergence in health expenditures, evidence of non-convergence have also been found in some other studies. Narayan (2007) tested the 'catch-up' hypothesis of per capita health expenditures. The author examined convergence in per capita health expenditures of five OECD countries (UK, Canada, Japan, Switzerland and Spain) to US per capita health expenditure between 1960 and 2000 . First, ADF test was used to test the stationarity of the US per capita health expenditures relative to each OECD country being examined. Test results showed 
no evidence of convergence of per capita health expenditures, while when LM univariate unit root tests allowing for structural breaks were applied, results suggested the existence of convergence. In addition to these, five countries were also considered as a panel and panel unit root tests were used. Similar results were obtained. Convergence of per capita health expenditures was present only when the structural breaks were taken into account. Aslan (2008) investigated the convergence of per capita health care expenditures for 19 OECD countries between 1970 and 2005 by using Lima and Resende (2007) persistence procedure. IPS panel data unit root test was implemented. Persistence in inequality in health care expenditures per capita was evident since the unit root tests could not be rejected.

Apart from convergence studies on OECD and EU countries, Wang (2009) examined the convergence in per capita health expenditure and its nine components for 50 states in US between 1980 and 2004. Those components were constructed by the type of establishment delivering care and the medical products purchased in retail outlets. A moderate evidence of convergence was found. In addition, convergence in hospital care explained most of the convergence in health care expenditures while prescription drugs, other personal health care and nursing home constituted as diverging factors. Unlike the aforementioned studies, Lau et al. (2014) considered nonlinear dynamics in health expenditure series. They investigated per capita health expenditure convergence among 14 EU countries between 1970 and 2008 implementing nonlinear panel unit root tests. Test results showed the existence of unit root for most of the countries studied relative to different benchmark countries including EU average. Hence, the results did not support the convergence hypothesis.

\section{DATA AND METHODOLOGY}

In this research, concept of convergence in per capita health expenditure was examined for 22 OECD countries (Australia, Austria, Belgium, Canada, Denmark, Finland, Germany, Iceland, Ireland, Israel, Japan, Korea, Netherlands, New Zealand, Norway, Portugal, Spain, Sweden, Switzerland, Turkey, the United Kingdom (UK) and the US) between 1980 and 2012. This sample of OECD countries was selected based on data availability. Per capita health expenditure series for all countries were PPP-adjusted US Dollar series over the period 1980-2012 and obtained from online OECD database: OECD Health
Statistics. Table 1 shows average GDP growth, GDP per capita, population and per capita health expenditures for each country over the period of 1980 and 2012. Korea has the highest average GDP growth $(6.43 \%)$ while Denmark has the smallest average GDP growth (1.67\%). The highest average GPD per capita belongs to Norway whereas Turkey has the smallest average GDP per capita as shown in the third column of Table 1. In terms of population, US has the highest average population among other countries while Iceland has the smallest average population over the period of 1980-2012. Finally, Turkey has lowest average per capita health expenditure among others whereas the highest average per capita health expenditure belongs to US. It is also observed that the countries with the smallest average GDP per capita (such as Turkey, Korea, Portugal, Israel, Spain and New Zealand) between 1980 and 2012 have also the lowest average per capita health expenditures. Norway and Switzerland with high average GDP per capita have also high average per capita health expenditures. On the other hand, Turkey, Israel and Korea as the countries with low average GDP per capita and average per capita health expenditures have higher average GDP growth than all other countries listed in Table 1.

First of all, each year per capita health expenditure series for each country was divided by the average per capita health expenditures of 22 OECD countries. That is, health expenditure per capita of country i relative to average per capita health expenditures among 22 OECD countries at time $t$ was constructed as below:

$$
y_{i t}=\ln \left(\frac{h_{i t}}{\bar{h}_{t}}\right)
$$

where $h_{i t}$ is per capita health expenditure for country $\mathrm{i}$ at time $t, \bar{h}_{t}$ is the average per capita health expenditure at time $t$ and $I n$ is the natural logarithm.

To test for the convergence of per capita health expenditures, three panel unit root estimation methods were employed: (1) IPS linear panel unit root test, (2) a symmetric nonlinear panel unit root test developed by Ucar and Omay (2009), and (3) an asymmetric nonlinear panel unit root test proposed by Emirmahmutoglu and Omay (2014). Some basics of Emirmahmutoglu and Omay (2014) methodology were introduced in this section as being the main focus of this study. 
Table 1: Average GDP Growth, GDP per Capita, Population and Health Expenditure

\begin{tabular}{|c|c|c|c|c|}
\hline Country & $\begin{array}{l}\text { GDP growth } \\
\text { (percent) }\end{array}$ & $\begin{array}{c}\text { GDP per capita (constant } \\
2005 \text { US\$) }\end{array}$ & Population & $\begin{array}{c}\text { Per capita } \\
\text { health expenditures }\end{array}$ \\
\hline Australia & 3.24 & 28310.69 & 18399912.12 & 1957.99 \\
\hline Austria & 2.11 & 32508.97 & 7934670.88 & 2441.95 \\
\hline Belgium & 1.94 & 31281.41 & 10235128.61 & 2114.39 \\
\hline Canada & 2.46 & 30595.55 & 29564925.39 & 2424.35 \\
\hline Denmark & 1.67 & 41358.75 & 5284686.88 & 2360.88 \\
\hline Finland & 2.40 & 31366.57 & 5100618.79 & 1807.38 \\
\hline Germany & 1.75 & 31015.50 & 80631051.85 & 2532.67 \\
\hline Iceland & 2.77 & 46094.03 & 272900.00 & 2274.88 \\
\hline Ireland & 4.21 & 33666.26 & 3832169.85 & 1769.24 \\
\hline Israel & 4.80 & 17070.88 & 5715330.30 & 1426.23 \\
\hline Japan & 2.12 & 31405.20 & 124608817.36 & 1757.97 \\
\hline Korea & 6.43 & 12896.68 & 44944051.88 & 785.83 \\
\hline Netherlands & 2.11 & 35088.34 & 15501570.82 & 2306.45 \\
\hline New Zealand & 2.51 & 23282.63 & 3718036.36 & 1461.50 \\
\hline Norway & 2.61 & 53367.35 & 4428475.21 & 2686.47 \\
\hline Portugal & 2.09 & 15615.88 & 10193310.36 & 1266.00 \\
\hline Spain & 2.41 & 21347.63 & 40887517.15 & 1418.32 \\
\hline Sweden & 2.10 & 35704.64 & 8787989.64 & 2183.35 \\
\hline Switzerland & 1.75 & 50348.82 & 7045121.24 & 2977.85 \\
\hline Turkey & 4.20 & 5745.92 & 59347198.52 & 366.47 \\
\hline United Kingdom & 2.14 & 32153.89 & 58747212.58 & 1686.22 \\
\hline United States & 2.68 & 36552.67 & 269499016.58 & 4405.60 \\
\hline
\end{tabular}

The numbers shown in this table show the average of the corresponding variable for each country over the period of $1980-2012$. GDP and population values were obtained from World Development Indicators.

In order to detect the presence of nonstationarity against asymmetric nonlinear but globally stationary ESTAR process, a testing procedure was developed by Emirmahmutoglu and Omay (2014). Firstly, a nonlinear asymmetric heterogeneous panel data model was constructed as below:

$\Delta y_{i t}=G_{i t}\left(\gamma_{1 i}, y_{i, t-1}\right)\left\{S_{i t}\left(\gamma_{2 i}, y_{i, t-1}\right) \rho_{1 i}\right.$

$\left.+\left(1-S_{i t}\left(\gamma_{2 i}, y_{i, t-1}\right)\right) \rho_{2 i}\right\} y_{i, t-1}+\varepsilon_{i t}$,

$G_{i t}\left(\gamma_{1 i}, y_{i, t-1}\right)=1-\exp \left(-\gamma_{1 i} y_{i, t-1}^{2}\right) \quad \gamma_{1 i} \geq 0$ for all $i$

$S_{i t}\left(\gamma_{2 i}, y_{i, t-1}\right)=\left[1+\exp \left(-\gamma_{2 i} y_{i, t-1}\right)\right]^{-1} \quad \gamma_{2 i} \geq 0$ for all $i$

where $\varepsilon_{i t} \sim \operatorname{iid}\left(0, \sigma_{i}^{2}\right)$. Equation (1) nests the panel symmetric ESTAR specification of the panel stationarity test developed by Ucar and Omay (2009) when $\rho_{1 i}=\rho_{2 i}=\rho_{i}$ for all $i{ }^{2}$ Next, Emirmahmutoglu and Omay (2014) extended equation (1) to account for

\footnotetext{
${ }^{2}$ See Ucar and Omay (2009) for details.
}

serially correlated errors by allowing for higher order dynamics as given below:

$$
\begin{aligned}
& \Delta y_{i t}=G_{i t}\left(\gamma_{1 i}, y_{i, t-1}\right)\left\{S_{i t}\left(\gamma_{2 i}, y_{i, t-1}\right) \rho_{1 i}+\left(1-S_{i t}\left(\gamma_{2 i}, y_{i, t-1}\right)\right) \rho_{2 i}\right\} \\
& y_{i, t-1}+\sum_{j=1}^{p_{i}} \delta_{i j} \Delta y_{i, t-j}+\varepsilon_{i t}
\end{aligned}
$$

Using equation (4), the unit root hypothesis can be tested against the alternative hypothesis of globally stationary symmetric or asymmetric ESTAR nonlinearity with a unit root central regime by testing $H_{0}: \gamma_{1 i}=0$ (Emirmahmutoglu and Omay 2014:186). However, there are unidentified parameters with this null hypothesis. Thus, the following augmented auxiliary equation (i.e. equation 5) was derived by Emirmahmutoglu and Omay (2014) using a Taylor approximation to solve this problem.

$\Delta y_{i t}=\phi_{1 i} y_{i, t-1}^{3}+\phi_{2 i} y_{i, t-1}^{4}+\sum_{j=1}^{p_{i}} \delta_{i j} \Delta y_{i, t-j}+\varepsilon_{i t}$

Based on equation (5), the null hypothesis was changed to $H_{0}: \phi_{1 i}=\phi_{2 i}=0$ for all $i$. The test statistic 
was constructed by taking the average of the individual $F_{i, A E}$ statistics developed by Sollis (2009). Hence, we have the following test statistic:

$$
\bar{F}_{A E}=N^{-1} \sum_{i=1}^{N} F_{i, A E} .
$$

As pointed out by Emirmahmutoglu and Omay (2014), since the panel $\bar{F}_{A E}$ test statistic has a nonstandard distribution, exact critical values of $\bar{F}_{A E}$ should be computed via stochastic simulation for different values of $N$ and $T$. They also noticed that if the disturbances are not independent, the limit distributions of the test statistics are unknown in the presence of cross correlations among the cross-section units. Thus, in order to overcome this problem Emirmahmutoglu and Omay (2014) implemented the Sieve bootstrap methodology proposed by Chang (2004) to obtain the empirical distributions of the bootstrap statistic $\bar{F}_{A E}^{*}{ }^{3}$

Finally, in order to identify stationary countries Emirmahmutoglu and Omay (2014) employed the SPSM procedure proposed by Choartareas and Kapetanios (2009). The steps of the SPSM procedure as outlined in Emirmahmutoglu and Omay (2014:189) are as follows:

1) Eq. (5) is first estimated for all the series in the panel. If the null hypothesis of a unit root is not rejected, then the non-stationary hypothesis is accepted and the procedure stops. In this case, all the series in the panel are found to be nonstationary. On the contrary, if the unit root null is rejected, one should move on to Step 2.

2) Drop the series with the maximum $\bar{F}_{A E}^{*}$ statistics that shows the strongest evidence in favor of stationarity and go to Step 3 .

3) Return to Step 1 for the remaining series, or stop the procedure if all the series are removed from the panel.

\section{RESULTS}

The first approach as mentioned before is a conventional linear panel unit root test developed by Im et al. (2003), namely IPS test. IPS test is conducted for the full sample of OECD countries and the test result implies that the null hypothesis of a unit root in the

\footnotetext{
${ }^{3}$ See Emirmahmutoglu and Omay (2014) and Chang (2004) for further details.
}

health expenditures relative to OECD mean cannot be rejected with the test value -1.295 as shown in Table 2 . Therefore, the conventional linear panel unit root test rejects the convergence hypothesis in the per capita health expenditures toward OECD mean for the whole panel of countries.

Next, existence of nonlinear mean reversion in the relative healthcare expenditure series is investigated by performing the other two panel unit root tests developed by Ucar and Omay (2009) (henceforth, UO) and Emirmahmutoglu and Omay (2014) (henceforth, EO). UO test is a nonlinear symmetric panel unit root ttest $\left(\bar{t}_{N L}\right)$ and EO test is an asymmetric panel unit root F-test $\left(\bar{F}_{A E}^{*}\right)$. The results of UO and EO nonlinear panel unit root tests presented in Table 2 employ the Sieve bootstrap methodology proposed by Chang (2004) in order to remedy the cross-sectional dependency problem. A sequence of $U O$ tests resulted from the SPSM procedure introduced in Section 3 are reported in column 2 of Table 2. The individual minimum KSS statistics given in column 3 are used to make decision about dropping the individual series i.e. countries from the panel. Finally, countries with stationary series identified using this procedure as shown in column 1 are sorted in a descending order according to the corresponding minimum KSS statistics. The same SPSM procedure is also applied for EO tests as shown in column 5 . The individual maximum F-statistics by Sollis (2009) that are used to drop the individual series are reported in column 6 of Table 2. Column 4 in Table 2 presents the stationary series identified with this procedure sorted in a descending order based on the corresponding maximum F-statistics.

According to the results of panel UO and EO tests (columns 2 and 5, respectively), the null hypothesis of a unit root in the healthcare expenditure relative to OECD mean is rejected when the UO and EO tests are applied to the full sample of countries (with values 1.589 and 3.743 , respectively). When the SPSM procedure is implemented for UO test, the relative healthcare expenditure series of Australia is found to be stationary with the minimum KSS statistics (-4.438). Therefore, UO test is applied on the remaining set of 21 countries with the removal of Australia from the panel. The new panel UO test result is now -1.453 implying that the null hypothesis of a unit root for the remaining 21 countries cannot be rejected. Thus, the SPSM procedure terminates at this stage for UO test. As a result, it can be concluded that only Australia healthcare expenditure series exhibits convergence to the mean of the per capita healthcare expenditures of 22 OECD countries based on panel UO test with the 
alternative hypothesis of symmetric nonlinear mean reversion in the series.

Using the same SPSM outlined above for EO test, Japan is found to be stationary with the highest maximum F-statistic 18.711 and so it is removed from the panel. After that, panel EO test is applied for the remaining 21 countries and EO test still rejects the null hypothesis of a unit root with the value of 3.031 . Since Australia is found to be stationary with the maximum Fstatistics 11.471 , it is dropped from the panel and EO test is implemented for the remaining 20 series in the panel. EO test with the value of 2.609 rejects the unit root null hypothesis and SPSM procedure continues until panel EO test fails to reject the null hypothesis of a unit root. Finally, the procedure stops when Korea is removed from the panel and EO test with the value of 2.079 fails to reject the unit root null hypothesis for the remaining countries. Hence, it can be concluded that per capita healthcare expenditure series for Australia, Japan, Korea, Spain and Sweden exhibit convergence to the mean of the per capita healthcare expenditures of 22 OECD countries by using panel EO test with the alternative hypothesis of asymmetric nonlinear mean reversion in the series.

Findings from Table 2 can be summarized as follows. The conventional symmetric linear IPS test

Table 2: Panel Unit Root Test Results

\begin{tabular}{|c|c|c|c|c|c|c|}
\hline $\begin{array}{c}\text { Countries } \\
\text { (descending order } \\
\text { based on column } 3 \text { ) }\end{array}$ & $\begin{array}{l}\text { Panel } \\
\text { UO Test } \\
\left(\bar{t}_{N L}\right)\end{array}$ & $\begin{array}{c}\text { Individual } \\
\text { Minimum KSS } \\
\text { Statistic }\end{array}$ & $\begin{array}{c}\text { Countries } \\
\text { (descending order } \\
\text { based on column } \\
6 \text { ) }\end{array}$ & $\begin{array}{c}\text { Panel } \\
\text { EO Test } \\
\left(\bar{F}_{A E}^{*}\right)\end{array}$ & $\begin{array}{c}\text { Individual } \\
\text { Maximum } \\
\text { F-Statistic } \\
\quad\left(F_{i, A E}\right)\end{array}$ & $\begin{array}{c}\text { Individual } \\
\text { EO } \\
\text { Asymmetry } \\
\text { Test }\end{array}$ \\
\hline Australia & $-1.589^{* * *}$ & $-4.438^{*}$ & Japan & $3.743^{*}$ & $18.711^{*}$ & $5.194^{*}$ \\
\hline Portugal & -1.453 & -2.646 & Australia & $3.031^{* *}$ & $11.471^{*}$ & 1.261 \\
\hline UK & -1.332 & -2.503 & Sweden & $2.415^{\star *}$ & $5.290^{* *}$ & $2.795^{\star *}$ \\
\hline Turkey & -1.267 & -2.133 & Korea & $2.256^{* * *}$ & $5.260^{* *}$ & $-3.210^{*}$ \\
\hline Germany & -1.216 & -1.942 & Finland & 2.079 & $4.300^{* * *}$ & $2.055^{\star \star}$ \\
\hline Japan & -1.171 & -1.911 & UK & 1.940 & 3.399 & 0.789 \\
\hline Denmark & -0.959 & -1.671 & US & 1.533 & 2.791 & $-1.949^{* \star}$ \\
\hline Canada & -0.894 & -1.529 & Netherlands & 1.418 & 2.735 & 1.420 \\
\hline Sweden & -0.831 & -1.510 & Canada & 1.286 & 2.632 & 1.534 \\
\hline Ireland & -0.755 & -1.455 & Norway & 1.137 & 1.989 & 1.415 \\
\hline Norway & -0.668 & -1.383 & Turkey & 1.030 & 1.949 & -0.007 \\
\hline US & -0.566 & -1.276 & Belgium & 0.899 & 1.609 & 0.580 \\
\hline Israel & -0.448 & -1.098 & Iceland & 0.781 & 1.232 & -1.381 \\
\hline Iceland & -0.317 & -0.735 & Austria & 0.691 & 1.223 & -1.563 \\
\hline \multicolumn{7}{|c|}{ Panel EO Asymmetry Test: 1.509} \\
\hline
\end{tabular}

Note 1: The critical values of the KSS i.e. Kapetanios, Shin and Snell (2003) statistics and Solis (2009) tests are - 3.48, - 2.93, and -2.66, and 6.891, 4.886 and 4.009 , respectively, for the significance levels $* \% 1,{ }^{* *} \% 5$ and ${ }^{* * *} \% 10$.

Note 2: The empirical distributions of the tests, generated by 5000 replications, are used to obtain their p-values. For all of the tests, lag length is chosen using Schwarz-Bayes Criterion (SBC), setting the maximum lag length at 8. 
rejects the healthcare expenditure convergence hypothesis for the whole panel. On the other hand, the healthcare expenditure convergence hypothesis cannot be rejected for one country, Australia, when the symmetric nonlinear panel unit root test i.e. UO test is applied. When the presence of asymmetry behavior in the series is considered by applying EO test, per capita health expenditure series for 4 more countries (Japan, Korea, Spain and Sweden) in addition to Australia are also found to be converging towards OECD mean, which amounts to a total of 23 percent of rejections of the unit root hypothesis for the whole sample. This increase in the number of rejections highlights the importance of taking the potential asymmetry into account when analyzing the convergence in the per capita health expenditure series. Nevertheless, although the possibility of asymmetric adjustment is considered, EO test does not provide a strong evidence of per capita health expenditure convergence. Almost 77 percent of countries with relative per capita health expenditures are still found to be nonconverging. To sum up, long-run mean reversion of the relative per capita health expenditure series in this paper cannot be strongly supported by either of the symmetric and the asymmetric panel unit root tests.

Finally, a panel EO asymmetry test is applied. The results of the test with the value of 1.509 given in Table 2 shows us that asymmetry does not exist for the full sample of countries whereas the individual EO asymmetry tests in column 7 (time series version of the panel EO asymmetry test) suggest that 7 out of 22 OECD countries are asymmetric. Therefore, the results of nonlinear asymmetric panel unit root test might be driven from the asymmetric behaviors of the individual relative health expenditure series. Hence, it can be claimed that the nonlinear asymmetric mean reversion is more suitable in the case of health expenditure convergence and the application of wrong specifications such as linear and nonlinear symmetric panel models may result in very erroneous findings. For further research, possibility of a structural break or joint effects of structural break and nonlinearity in health care expenditure convergence can be analyzed by incorporating the asymmetric behavior.

\section{CONCLUSION}

This research examines the hypothesis of convergence in per capita health expenditures across countries. Per capita health expenditure data collected for 22 OECD countries are analyzed using panel unit root tests. The nonlinear asymmetric heterogenous panel unit root test methodology applied in this paper makes two main contributions to the literature on health expenditure convergence. Firstly, the Sieve bootstrap method developed by Chang (2004) is implemented to remedy the problems regarding cross-sectional dependency in a panel context. Secondly, it also allows for asymmetric nonlinear mean reversion. The null hypothesis of a unit root cannot be rejected by linear panel unit root test which indicates that countries as a panel do not converge to OECD mean. On the contrary, when the nonlinear symmetric and asymmetric panel unit root tests (UO and EO tests respectively) are employed, countries are found to be converging as a panel. The nonlinearity in health expenditure series can be explained by a theoretical justification. It is likely that income convergence exhibit nonlinearity (Datta 2003) and there have been studies considering nonlinear dynamics in income (Chong et al. 2008; King and Ramlogan-Dobson 2011; Nyong and Omobitan 2013). Since the national income and health expenditures are strongly correlated, it can be stated that health care expenditure series can also follow nonlinear path. In addition, as stated in Lau et al. (2014) 10 EU countries, which are also included in this study, exhibit nonlinear dynamics and linear unit root tests have low power to differentiate between nonlinearity (e.g. due to structural break) and nonconvergence. ${ }^{4}$ Hence, nonlinearity seems to be a plausible assumption for the health expenditure series. Therefore, different conclusions obtained from IPS test and the other two tests (UO and EO tests) can be explained by the differences in the underlying assumptions of the test statistics. That is, taking into account nonlinearity using $\mathrm{UO}$ and EO tests reveals the convergence behavior in the series as a panel.

In order to differentiate between stationary and nonstationary series, the SPSM procedure is employed for both $\mathrm{UO}$ and EO tests. Application of this procedure for UO test indicates that only one country converges towards OECD average while when the same procedure is applied for EO tests, 4 more countries are found to be converging. Therefore, incorporating asymmetric behavior via EO test provides us a way to uncover additional converging countries. In addition to these, presence of asymmetric behavior in the series are shown by the individual asymmetry test results.

\footnotetext{
${ }^{4}$ Those countries are Austria, Belgium, Denmark, Finland, Ireland, Netherlands, Portugal, Spain, Sweden and the UK.
} 
Even if the results do not give strong support of convergence for all countries, taking asymmetry into account seems to be the most suitable approach to analyze convergence in health expenditures. Thus, in order to designate a health policy target, countries should take into account the findings from methodologically correct studies. There can be several reasons for not finding a strong evidence of convergence for all countries using EO test. As indicated by Alcalde-Unzu et al. (2009), disparities in health expenditures across OECD countries can be explained by the differences in labor productivity and share of GDP devoted to health expenditures. In addition, healthcare provision measured by health employment, medical equipment and hospital beds vary across EU member countries (Montarani and Nelson 2013), some of which are also included in this research. ${ }^{5}$ Similarly, 11 countries that are examined in this paper and also EU members have different adaptation levels of healthcare policies leading to differentials in progress in implementation (Spencer and Walshe 2009). ${ }^{6}$ This may imply that a much longer period of time is needed to observe convergence across countries examined in this paper.

The findings of this research also suggest some policy implications regarding health expenditure convergence across countries. Demographic change, especially population aging, result in varying levels of health expenditures both within and between nations and so it is a key tool for the health policy makers to adapt new strategies considering demographic differences. Health care spending is one of the major item in public spending and so it creates a pressure in government budget (Docteur and Oxley 2003; OECD 2010). Not only aging population but also rising health care prices and high-cost medical technology are boosting health care budget (OECD 2010). Increase in health care spending may lead to decrease in spending in elsewhere in the economy such as education and other social services. This fear of increased health spending may preclude convergence across countries. Thus, instead of pouring money into health aimlessly, the policy makers should focus on ways to increase efficiency of health care system within a country. More effective and efficient health care system might be

\footnotetext{
${ }^{5}$ They are Austria, Belgium, Denmark, Finland, Germany, Ireland, Netherlands, Portugal, Spain, Sweden and the UK.

${ }^{6}$ The countries are Austria, Belgium, Denmark, Finland, Germany, Ireland, Netherlands, Portugal, Spain, Sweden and the UK.
}

achieved through improving quality of health care systems. For example, several countries including Austria and Finland should focus on quality out-patient sector for efficiency (OECD 2010). However, efficiency gains through health outcomes differ across OECD countries. While Germany, the UK and the US can improve health outcomes by exploiting efficiency gains in health sector, majority of OECD countries still need to increase health spending to achieve better health outcomes (OECD 2010). To sum up, there is no health care system that fits to all OECD countries. Therefore, in order to have consistent health policies across OECD members, policy makers should adapt best approaches available among different health care systems existing in OECD countries (OECD 2010).

Achieving convergence across countries can promote economic growth by encouraging countries to make expenditures on health care in a cost effective way. Investment on medical technology, for instance, increases when the countries grow. At the same time, countries can promote healthy workforce by reducing the incidence of diseases through medical improvements. Therefore, increasing government spending on health care through medical technology can increase productivity and promote economic growth. Furthermore, in Grossman (1972) model an individual is assumed as both the consumer and the producer of health. This makes health a consumption good that gives direct satisfaction to individuals and an investment good that promotes healthy time which increases productivity as well. Hence, any government policy on health (e.g. reducing queuing time) affects the utilization of health care by consumers and so the health expenditures. Eventually, productivity and economic growth can be improved with the government policies.

\section{REFERENCES}

Alcalde-Unzu, Jorge, Roberto Ezcurra, and Pedro Pascual. 2009. "Cross-Country Disparities in Health-Care Expenditure: A Factor Decomposition." Health Economics 18(4):479-485. http://dx.doi.org/10.1002/hec.1374

Aslan, Alper. 2008. "Convergence of per Capita Health Care Expenditures in OECD Countries." MPRA Paper No: 10592.

Boyle, G. E. and T. G. McCarthy. 1999. "Simple Measures of Convergence in per Capita GDP: A Note on Some Further International Evidence." Applied Economics Letters 6(6):343347.

http://dx.doi.org/10.1080/135048599353041

Chang, Yoosoon. 2004. "Bootstrap Unit Root Tests in Panels with Cross-Sectional Dependency." Journal of Econometrics 120(2):263-293. http://dx.doi.org/10.1016/S0304-4076(03)00214-8 
Chong, Terence T., Melvin J. Hinich, Venus K. Liew, and Kian-Ping Lim. 2008. "Time Series Test of Nonlinear Convergence and Transitional Dynamics." Economics Letters 100(3):337-339. http://dx.doi.org/10.1016/j.econlet.2008.02.025

Chortareas, Georgios and George Kapetanios. 2009. "Getting PPPR Right: Identifying Mean-reverting Real Exchange Rates in Panels." Journal of Banking and Finance 33(2):390-404. http://dx.doi.org/10.1016/j.jbankfin.2008.08.010

Datta, Anusua. 2003. "Time Series Test of Convergence and Transitional Dynamics." Economics Letters 81(2):233-240. http://dx.doi.org/doi:10.1016/S0165-1765(03)00186-1

Docteur, Elizabeth and Howard Oxley. 2003. "Health Care Systems: Lessons from the Reform Experience." OECD Health Working Papers. OECD, Paris. http://dx.doi.org/10.1787/884504747522

Emirmahmutoglu, Furkan and Tolga Omay. 2014. "Reexamining the PPP Hypothesis: A Nonlinear Asymmetric Heterogeneous Panel Unit Root Test." Economic Modelling 40:184-190. http://dx.doi.org/10.1016/j.econmod.2014.03.028

Fallahi, Firouz. 2011. "Convergence of Total Health Expenditure as a Share of GDP: Evidence from Selected OECD Countries." MPRA Paper No: 51324.

Grossman, Michael. 1972. "On the Concept of Health Capital and the Demand for Health." Journal of Political Economy 80(2):223255. http://dx.doi.org/10.1086/259880

Hitiris, Theo and John Nixon. 2001. "Convergence in Health Care Expenditure in the EU Countries." Applied Economics Letters 8(4):223-228. http://dx.doi.org/10.1080/135048501750103890

Huber, Manfred and Eva Orosz. 2003. "Health Expenditure Trends in OECD Countries, 1990-2001." Health Care Financing Review 25(1):1-22.

Im, Kyung S., M. Hashem Pesaran, and Yongcheol Shin. 2003. "Testing for Unit Roots in Heterogeneous Panels." Journal of Econometrics 115(1):53-74. http://dx.doi.org/10.1016/S0304-4076(03)00092-7

Kapetanios, George, Yongcheol Shin, and Andy Snell. 2003. "Testing for a Unit Root in the Nonlinear STAR Framework." Journal of Econometrics 112(2):359-379. http://dx.doi.org/10.1016/S0304-4076(02)00202-6

Kerem, Kaie, Tiia Püss, Mare Viies, and Reet Maldre. 2008. "Health and Convergence of Health Care Expenditure in EU." International Business \& Economics Research Journal 7(3):29-44.

King, Alan and Carlyn Ramlogan-Dodson. 2011. "Nonlinear TimeSeries Convergence: The Role of Structural Breaks." Economic Letters 110(3):238-240. http://dx.doi.org/10.1016/j.econlet.2010.12.001

Kwiatkowski, Denis, Peter C. B. Phillips, Peter Schmidt, and Yongcheol Shin. 1992. "Testing the Null Hypothesis of Stationary against the Alternative of a Unit Root." Journal of Econometrics 54(1-3):159-178. http://dx.doi.org/10.1016/0304-4076(92)90104-Y

Lau, Chi K. M., Ka W. T. Fung, and Lee Pugalis. 2014. "Is Health Care Expenditures Across Europe Converging?" Eurasian Business Review 4(2):137-156. http://dx.doi.org/10.1007/s40821-014-0014-9

Lee, Junsoo and Mark C. Strazicich. 2003. "Minimum LM Unit Root Tests with Two Structural Breaks." Review of Economics and Statistics 85(4):1082-1089. http://dx.doi.org/10.1162/003465303772815961

Lima, Marcos A. M. and Marcelo Resende. 2007. "Convergence of per Capita GDP in Brazil: An Empirical Note." Applied Economic Letters 14(5):333-335. http://dx.doi.org/10.1080/13504850500461381
Montanari, Ingalill and Kenneth Nelson. 2013. "Social Services Decline and System Convergence: How Does Health Care Fare?" Journal of European Social Policy 23(1):102-116. http://dx.doi.org/10.1177/0958928712456574

Narayan, Paresh K. 2007. "Do Health Expenditures Catch-up? Evidence from OECD Countries." Health Economics 16(10):993-1008.

http://dx.doi.org/10.1002/hec.1196

Narayan, Paresh K. 2009. "Are Health Expenditures and GDP Characterized by Asymmetric behavior? Evidence from 11 OECD Countries." Applied Economics 41(4):531-536. http://dx.doi.org/10.1080/00036840701765304

Newhouse, Joseph P. 1992. "Medical Care Costs: How Much Welfare Loss?" The Journal of Economic Perspectives 6(3):3-21. http://dx.doi.org/10.1257/jep.6.3.3

Nixon, John. 2000. "Convergence of Health Care Spending and Health outcomes in the European Union, 1960-1995." Discussion paper No: 183. Centre for Health Economics, University of York.

Nyong, Michael O. and Olufunsho A. Omobitan. 2013. "Nonlinear Income Convergence and Structural Breaks: Further Empirical Evidence." International Journal of Economics and Finance 5(4):81-88. http://dx.doi.org/10.5539/ijef.v5n4p81

Organization for Economic Cooperation and Development (OECD). 2010. "Health Care Systems: Getting More Value for Money." OECD Economics Department Policy Notes No. 2. OECD, Paris.

Organization for Economic Cooperation and Development (OECD). 2013. "Health at a Glance 2013: OECD Indicators." OECD, Paris. http://dx.doi.org/10.1787/health glance-2013-en

Okunade, Albert A. and Vasudeva N. R. Murthy. 2002. "Technology as a 'Major Driver' of Health Care Costs: A Cointegration Analysis of the Newhouse Conjecture." Journal of Health Economics 21(1):147-159. http://dx.doi.org/10.1016/S0167-6296(01)00122-9

Panopoulou, Ekaterini and Theologos Pantelidis. 2011. "Convergence in per Capita Health Expenditures and Health Outcomes in OECD Countries." Applied Economics 44(30):3909-3920. http://dx.doi.org/10.1080/00036846.2011.583222

Phillips, Peter C. B. and Donggyu Sul. 2007. "Transition Modeling and Econometric Convergence Tests." Econometrica 75(6):1771-1855. http://dx.doi.org/10.1111/j.1468-0262.2007.00811.x

Schmitt, Carina and Peter Starke. 2011. "Explaining Convergence of OECD Welfare States: A Conditional Approach." Journal of European Social Policy 21(2):120-135. http://dx.doi.org/10.1177/0958928710395049

Sollis, Robert. 2009. "A simple Unit Root test against asymmetric STAR nonlinearity with and application to real exchange rates in Nordic countries." Economic Modelling 26(1):118125.

http://dx.doi.org/10.1016/j.econmod.2008.06.002

Spencer, E. and K. Walshe. 2009. "National Quality Improvement Policies and Strategies in European Healthcare Systems." Qual Saf Health Care 18(Suppl 1):i22-i27. http://dx.doi.org/10.1136/qshc.2008.029355

Taylor, Mark P. and Lucio Sarno. 1998. "The Behavior of Real Exchange Rates during the Post-Bretton Woods Period." Journal of International Economics 46(2):281-312. http://dx.doi.org/10.1016/S0022-1996(97)00054-8

Ucar, Nuri and Tolga Omay. 2009. "Testing for Unit Roots in Nonlinear Heterogeneous Panels." Economics Letters 104(1):5-8.

http://dx.doi.org/10.1016/i.econlet.2009.03.018 
Vogelsang, Timothy J. 1998. "Trend Function Hypothesis Testing in the Presence of Serial Correlation." Econometrica 66(1):123148.

http://dx.doi.org/10.2307/2998543
Wang, Zijun. 2009. "The Convergence of Health Care Expenditures in the US States." Health Economics 18(1):55-70. http://dx.doi.org/10.1002/hec.1343

Received on 20-03-2015

Accepted on 06-04-2015

Published on 16-04-2015

DOI: http://dx.doi.org/10.6000/1929-7092.2015.04.07

(C) 2015 Didem Pekkurnaz; Licensee Lifescience Global.

This is an open access article licensed under the terms of the Creative Commons Attribution Non-Commercial License (http://creativecommons.org/licenses/by-nc/3.0/) which permits unrestricted, non-commercial use, distribution and reproduction in any medium, provided the work is properly cited. 